\title{
EL CONFESOR REGIO FRAY LUIS ALIAGA Y LA CONTROVERSIA INMACULISTA
}

\author{
POR \\ EMILIO CALLADO ESTELA \\ Universidad CEU Cardenal Herrera. Valencia \\ ecallado@uch.ceu.es
}

\begin{abstract}
RESUMEN
El presente artículo analiza la participación del dominico aragonés fray Luis Aliaga (Zaragoza, 1565-† Zaragoza, 1626) , último confesor de Felipe III e Inquisidor general de la Monarquía Hispánica desde 1619, en una de las controversias teológicas más candentes a lo largo del siglo XVII: la Inmaculada Concepción de la Virgen María.

PALABRAS CLAVE: Inmaculada Concepción, siglo XVII, dominicos, fray Luis Aliaga, Confesor real, Felipe III.

\section{THE ROYAL CONFESSOR LUIS ALIAGA AND THE CONTROVERSY ON THE IMMACULATE CONCEPTION OF THE VIRGIN MARY}

\begin{abstract}
The present article analyses the participation of the aragonese dominican monk Luis Aliaga (Zaragoza, 1565- $†$ Zaragoza, 1626), last confessor of Philip III and Inquiring general of the Hispanic Monarchy from 1619, in one of the most white hot theological controversies along the 17th century: the Immaculate Conception of the Virgin Mary.
\end{abstract}

KEY WORDS: Immaculate Conception, $17^{\text {th }}$ century, Dominicans, Luis Aliaga, Royal confessor, Philip III.

Recibido/Received 07-11-2013

Aceptado/Accepted 07-08-2014
Entre las controversias teológicas libradas a lo largo del siglo XVII ocuparía un lugar de honor la suscitada en torno a la Inmaculada Concepción de la Virgen María, cuya causa habían abrazado los Austrias españoles ya en la centuria anterior. Desde entonces, los sucesivos monarcas empezaron a luchar por una declaración pontificia favorable a este misterio mariano que pusiera fin a los combates entre inmaculistas y maculistas. Este último partido andaba encabezado por los dominicos, entre los que destacarían nombres tan notables como el del último confesor de Felipe III fray Luis Aliaga, fiel a la tesis oficial sostenida por la orden de Predicadores al respecto de la Pureza de la Madre de Dios. Como abanderado del maculismo, en efecto, el religioso hizo lo imposible por obstaculizar desde Madrid cualquier avance de la causa contraria, ya fuera en la propia corte o en la misma Roma. Actuaría siempre habilidosamente, en evitación de enemistades con la monarquía o el papado que pudieran frustrar su promoción personal; de una manera más soterrada al principio, y de modo flagrante después, sobre todo desde su incorporación a las diferentes juntas reunidas a petición del soberano para arrojar luz sobre un asunto que la Santa Sede no tenía intención de innovar en absoluto. Precisamente el pontífice Paulo $\mathrm{V}$, a través de los nuncios destacados en España, Antonio Caetani y Francesco Cennini, iba a encontrar en nuestro protagonista al mejor de los aliados para que así fuera.

\section{SIN PECADO CONCEBIDA}

La polémica sobre María Inmaculada, que desde tiempos medievales venía enfrentando a escuelas teológicas y órdenes religiosas, había entrado de lleno en la época moderna sin que la Iglesia tomara una firme decisión al respecto para atajarla mediante su confirmación dogmática, dilatada aún hasta mediados del Ochocientos. ${ }^{1}$ No lo hizo el pontífice Sixto IV, al aprobar la fiesta de la Purísima con la concesión de algunas indulgencias. ${ }^{2}$ Pero tampoco

1 Le Bachelet, X. 1927. "Immaculée Conception", en Dictionnaire de Théologie Catholique : VII, 1120 y ss. París : Gaume fréres et J. Duprey editeurs.

2 Llorca, B. 1954. "La autoridad eclesiástica y el dogma de la Inmaculada Concepción”. Estudios Eclesiásticos 28: 308. 
el concilio de Trento, cuya cautela en esta materia apenas contribuyó a mejorar la situación. ${ }^{3}$ En la misma línea, Pío V se limitó en 1570 a prohibir las disputas y altercados producidos, cada vez con mayor frecuencia, entre los partidarios de uno y otro sentir. Ninguno de ellos depuso su actitud, inaugurando la decimoséptima centuria inmersos en una verdadera batalla campal finalmente extendida al pueblo. $^{4}$

Tan singular combate tuvo un escenario privilegiado en el ámbito hispánico, donde la devoción inmaculista pasó a ser una de las manifestaciones más relevantes de la religiosidad popular barroca, convertida en auténtico asunto de estado durante las postrimerías del reinado de Felipe III, tras las escaramuzas acontecidas en Sevilla, desde 1613, a manos de miembros de ambos bandos. ${ }^{5}$

Ya entonces se dejó sentir la influencia del titular del primer confesionario de la Monarquía, el dominico fray Luis Aliaga. ${ }^{6}$ Había nacido éste allá por 1565 en Zaragoza, donde

3 Olazarán, J. 1946. "El dogma de la Inmaculada Concepción en el concilio de Trento". Estudios Eclesiásticos 20: 107-136; y Sagües, J. 1954. "Trento y la Inmaculada. Naturaleza del dogma mariano", Estudios Eclesiásticos 28: 323-367.

4 Vázquez, I. 1979. "Las controversias doctrinales postridentinas hasta fines del siglo XVII", en Historia de la Iglesia en España IV. La Iglesia en la España de los siglos XVII y XVIII: 457-458. Madrid: Biblioteca de Autores Cristianos.

5 Véanse, entre otros, Bonnefoy, J. F. 1955. "Sevilla por la Inmaculada". Archivo Iberoamericano XV: 7-33; Vranic, S. 1966. "Carta de un ciudadano de Sevilla. La Guerra mariana de Sevilla en el siglo XVII". Archivo Hispalense XLIV: 241-274, y XLV: 59-77; Ros, C. 1988. La Inmaculada y Sevilla. Sevilla: Editorial Castillejo, 1988; y Cortés Peña, A. L. 2001. "Andalucía y la Inmaculada Concepción en el siglo XVII", en Calderón de la Barca y la España del Barroco: I, 401-428. Madrid:, Centro de Estudios Políticos y Constitucionales.

6 A la espera de una biografía completa sobre el personaje, en la que ahora trabajamos, puede verse Navarro Latorre, J. 1981. "Aproximación a fray Luis de Aliaga, confesor de Felipe III e Inquisidor General de España", en Estudios del Departamento de Historia Moderna. Zaragoza: Universidad de Zaragoza; Poutrin, I. 1997. "L'oeil et le souverain: Luis de Aliaga et le métier de confesseur royal sous Philippe III", en J. M. Scholz y Th. Herzog (Dirs.), Observation and Communication: The construcction of realities in the Hispanic World: 253-270. Franfuert am Main: s.e.; y García García, B. J. 1998. "El confesor fray Luis Aliaga y la conciencia del rey", en I religiosi a corte, teologia politica e diplomazia in Antico Regime: 159-194. Florencia: Bulzoni Editore. También Callado Estela, E. 2002. "Parentesco y lazos de poder. Las relaciones del arzobispo de Valencia fray Isidoro Aliaga con su hermano fray Luis Aliaga, confesor regio e Inquisidor General", en Espacios de poder. Cortes, ciudades y villas (s. XVI-XVIII): I, 123-138. Madrid: Universidad Autónoma; 2013 "Del Cielo a los Infiernos. Cénit y nadir del confesor regio fray Luis Aliaga", en Las artes y la arquitectura del poder: 2303-2321. Castellón de la Plana: Universitat Jaume I; 2013 "Un testimonio inédito contra la expansión conventual en la España de Felipe III". Studia Philologica Valentina. Filologia, literatura, historia y pensamiento en la época de san Juan de Ribera 15-12: 149-168; 2014 El confesor regio fray Luis Aliaga y la cuestión morisca. Investigaciones históricas 34: 27-46; y "La Prima Vita del dominico fray Luis Aliaga, confesor regio e Inquisidor general", en XIV Reunión Científica de la Fundación Española de Historia Moderna. Religión, tolerancia(s) y sociedad en el mundo hispánico de la Edad Moderna, este último en prensa. Especial mención merece, por el tema de que se ocupa el ya clásico trabajo de Canal, M. 1932. "El padre Luis de Aliaga y las controversias teológicas de su tiempo", Archivium Fratrum Praedicatorum X: 107-157, primera y sucinta incursión en el tema de las presentes páginas a partir de algunos documentos localizados por el autor en el Archivo General de la Orden de Predicadores [=AGOP]. su familia regentaba un modesto comercio de paños. ${ }^{7}$ Como su hermano menor Isidoro, fue acogido tempranamente bajo la protección del padre Xavierre, por aquellas fechas prior del convento de Predicadores de esta localidad. ${ }^{8}$ En tal cenobio ingresó el joven Aliaga, que hizo su profesión religiosa el 3 de noviembre de 1582, de manos del propio fray Jerónimo. ${ }^{9}$ A su lado -ya como fray Luis- trabajó en los orígenes del colegio dominicano de San Vicente Ferrer y de la Universidad cesaraugustana. Del primero fue alumno aventajado, llegando a obtener los grados de lector y maestro en Teología; ${ }^{10}$ de la segunda, catedrático de esta misma materia hasta su renuncia en 1605 para dirigir el convento de San Ildefonso, erigido en Zaragoza bajo el mandato del nuevo Maestro General de la orden, no otro que el padre Xavierre. ${ }^{11}$ Auxilió a éste en el gobierno del orbe dominicano, en calidad de socio y con el título de Provincial de la Tierra Santa de Jerusalén y Visitador de Portugal. ${ }^{12}$ Concluido el generalato de su mentor, fray Luis Aliaga permaneció junto a él en la corte ocupándose de la conciencia del duque de Lerma, de quien se convirtió en hechura. ${ }^{13} \mathrm{~A}$ finales de 1608 , y apoyado por el valido, al que pronto daría la espalda para volar por libre y unirse al duque de Uceda en el monopolio de la confianza regia, había sustituido al padre Xavierre al frente del confesionario filipino. ${ }^{14}$

Desde tan privilegiada posición, fray Luis participó en la controversia de auxiliis por entonces ventilada, en la que tan activamente había tomado partido la orden de Predicadores. ${ }^{15}$ Y lo haría también el dominico, algo más tarde y apaciguada aquélla, en la otra gran polémica teológica de la época, esta vez en torno a la Inmaculada

7 Archivo Histórico Nacional [=AHN]. Inquisición. Leg. 1.306, exp. 3.

8 Blasco de Lanuza, V. 1622. Historias eclesiásticas y seculares de Aragón en que se continúan los Anales de Çurita, desde el año 1556 hasta el de 1618: II, 554. Zaragoza: Juan de Lanaia y Quartanet.

9 AHPDA [=Archivo Histórico de la Provincia Dominicana de Aragón]. Libros de Predicadores de Zaragoza. Ms. 1, Libro de profesiones del convento de Predicadores de Zaragoza: 7v.

10 Callado Estela, E. 2005. "Documentos para la Historia del dominicano colegio zaragozano de San Vicente Ferrer". Archivum Fratrum Praedicatorum LXXV: 182-183.

11 Borao, G.1869. Historia de la Universidad de Zaragoza: 113. Zaragoza: Imprenta de Calixto Ariño.

12 Latassa y Ortín, F. 1799. Biblioteca nueva de los escritores aragoneses que florecieron desde el año de 1600 hasta 1640. Tomo II: 376. Pamplona: Oficina de Joaquín de Domingo.

13 Pérez Bustamante, C. 1950. Felipe III. Semblanzas de un monarca y perfiles de una privanza: 95 y ss. Madrid: Real Academia de la Historia; y Feros, A.2002. El duque de Lerma. Realeza y privanza en la España de Felipe III: 234 y ss. Madrid: Marcial Pons.

14 Archivo General del Palacio Real [=AGPR]. Expedientes personales. Caja 45, exp. 33, Título de confesor de vuestra magestad para el maestro fray Luis de Aliaga. Una primera aproximación al balance de este periodo del confesionario regio presidido por fray Luis en Martínez Peñas, L. 2007. El confesor del rey en el Antiguo Régimen: 396-430. Madrid: Editorial Complutense.

15 Serry, J.-H. 1700. Historiae congregationum de auxiliis divinae gratiae sub sumnis pontificibus Clemente VIII et Paulo V. París: Apud Antonium Dezallier. También, desde la óptica jesuítica, Astrain, A.1912. Historia de la Compañía de Jesús en la asistencia de España: IV. Madrid: Razón y Fe. Sobre la intervención de nuestro protagonista en el caso, véase además del trabajo de M. Canal antes citado Lopetegui, I. 1974. "Renovación y fracaso de las tentativas para obtener una definición dogmática en la controversia de auxiliis". Archivo Teológico Granadino 37: 45-81. 
Concepción de la Virgen. En ella, no actuó sino mediatizado por el parecer que a este respecto había defendido santo Tomás de Aquino, quien, siguiendo a Pedro Lombardo, aceptó que María hubiese sido santificada in utero, lo que comportaba su carencia de pecado al nacer, no al ser concebida. ${ }^{16}$ Tal doctrina, que absolvía pero no libraba a la Madre de Dios de la mácula original, habíase hecho común a buena parte de la religión dominicana convertida para la posteridad en la bestia negra de la Pura Concepción. ${ }^{17}$

Se entiende, pues, que nuestro protagonista amparara en 1615 a sus hermanos de hábito hispalenses frente a la marabunta inmaculista fomentada por el arzobispo del lugar don Pedro de Castro y Quiñones, responsable del silencio impuesto a éstos en la materia, y por tanto de su indefensión, sobre la que llamaron la atención algunos deudos de los frailes Predicadores:

"Vémoslos aborrecidos del pueblo, y que falta para ellos no sólo la caridad piadosa que se debe a los religiosos, sino el trato ordinario de próximos, excusándose de su comunicación, excluyéndolos de hospedaje, negándoles aún el sustento por el dinero, menospreciados de la chusma, cantados y mofados de la gente vil, seguidos de los muchachos apedreados, y que han avido menester en ocasiones manos y pies para librarles de su furor". ${ }^{18}$

Así las cosas, el padre Aliaga estuvo detrás de la obtención de un par de cartas reales en auxilio de los dominicos de Sevilla. La primera, dirigida al Consejo de Estado, ordenando se tomaran las prevenciones necesarias para que los hijos de santo Domingo dejaran de ser molestados. Y la segunda, en este caso para el nuncio Antonio Caetani, arzobispo de Capua, con quien además de compartir educación escolástica y teológica mantenía una fluida relación, ${ }^{19}$ encareciéndole escribiese a los superiores de las órdenes regulares contrarias, franciscanos y jesuitas,

16 La fórmula tomista en cuestión decía así: "Beata Virgo contraxit quidem originale peccatum, sed ab eo fuit mundata antequam ex utero nasceretur". Santo Tomás de Aquino, Summa Theologiae, vol. III, q. 27, art. 2. Pese a todo, la opinión que este misterio mariano mereció al Aquinate ha suscitado desde siempre una airado debate, sosteniendo algunos autores que el dominico no sólo no contrarió a la Purísima, sino que se contó entre sus más ardientes defensores. Uno de los primeros en así afirmarlo fue el premostratense fray Felipe Bernal quien en 1623, en su obra Sentencia de sancto Tomás a favor de la Inmaculada Concepción de la Virgen María, escribió "el primero soy que saca a la luz libro atribuyendo la defensa de la Inmaculada Concepción de la Virgen Madre de Dios al príncipe de la Theología escolástica, sancto Thomás de Aquino". Cit. Zamora Mendoza, J. 1956. "Un logroñés ardiente defensor de la Inmaculada. Fray Felipe Bernal de Mena, religioso premostratense". Berceo 40: 291.

17 Una revisión de la problemática de la escuela dominicana en relación a la Purísima en 1955. De Immaculata Conceptione in ordine sancti Dominici. Virgo Immaculata. Acta congressus Mariologici Mariani Romae anno MCMLIV celebrati VI, Roma: s.e.

18 Cit. Frías, L. 1904. "Felipe III y la Inmaculada Concepción. Instancias a la Santa Sede por la definición del misterio". Razón y Fe 10: 30 .

19 Meseguer Fernández, J. 1955. "La Real Junta de la Inmaculada Concepción (1616-1817 / 20)”, Archivo Iberoamericano XV: 638. básicamente, ${ }^{20}$ apelando a su caridad con los religiosos dominicos. ${ }^{21}$

El ordinario hispalense, entretanto, no perdió el tiempo y desplazó a la corte dos prebendados para convencer al rey de la oportunidad de enviar a la Santa Sede una embajada que solicitase la definición dogmática del misterio mariano en lid. Recibidos por el monarca, los emisarios fueron derivados al confesor, cuyas palabras de aliento hacia ambos se contradijeron con su dictamen particular sobre el asunto elevado en secreto a Felipe III, desaconsejando las instancias a Roma en el sentido solicitado. ${ }^{22}$

Con todo, en junio de 1616 , el convencimiento del soberano y la insistencia del inmaculismo llevarían a la corona a reunir una primera junta de teólogos, integrada por los obispos de Santiago, Cuenca y Valladolid -respectivamente don Juan de Guevara, don Andrés Pacheco y don Francisco Sobrino- para asesorarse en esta materia. De poco serviría que la presidencia de la misma recayera en el nuncio, opuesto como el padre confesor a cualquier recurso a la Santa Sede, que nada quería innovar a propósito de esta pía opinión. Primero, por seguir el ejemplo de los anteriores pontífices y del mismo concilio de Trento, que a pesar del sentir mayoritario favorable a la Purísima no habían creído oportuno definir este misterio. Segundo, por no zanjar dogmáticamente sino aquellas cuestiones estrictamente necesarias para la salvaguarda de la fe. Y tercero, el temor a los herejes, quienes a buen seguro aprovecharían tal confirmación para atacar más al papado. ${ }^{23}$ Aún así, los tres obispos consultados se mostraron unánimes en su recomendación de solicitar a Paulo $\mathrm{V}$, por medio de un embajador extraordinario, la definición que muchos reclamaban, o al menos una declaración formal que impusiera silencio a sus contradictores. ${ }^{24}$

Fray Plácido de Tosantos, ex -General de la congregación vallisoletana de San Benito, sería el escogido por el soberano para encargarse de la misión, sin que Antonio Caetani y el padre Aliaga pudieran evitarlo. Sería el mismo papa, no obstante, quien demostrara la inutilidad de esta legacía, al promulgar en el mes de agosto el breve Regis

20 El dominico fray Antonio de Viedma escribía por estas mismas fechas, a propósito de esos últimos, que "han mostrado en esta ocasión ser verdad lo que la orden siempre a dicho que son: perpetuos y constantes enemigos de nuestra religión; nunca entendí tal, antes pensaba que deseaban nuestra amistad. E visto lo contrario, que no procuran sino nuestra total ruina". Cit. Canal, M. 1932: 141. Sobre el papel de los nuncios al respecto de esta controversia, véase el reciente artículo de Broggio, P. 2013. "Teologia, ordini religiosi e rapporti política: la questione dell'Immacolata Concezione di Maria tra Roma e Madrid (16141663)". Hispania Sacra LXV: 255-281. Del mismo autor, igualmente interesante para el tema que nos ocupa, 2009. La teología e la política. Controversie dottrinale, curia romana e monarchia spagnola tra Cinque e Seicento. Florencia: Leo S. Olschki Editore.

21 Frías, F.,1904: 31-32.

22 Meseguer Fernández, J. 1955: 632-633.

23 Gutiérrez, C. 1955. "España por el dogma de la Inmaculada. La embajada a Roma de 1659 y la bula Sollicitudo de Alejandro VII". Miscelanea Comillas 24: 17-18.

24 Archivo de la Embajada de España ante la Santa Sede [=AEESS]. Ms. 446, Relación histórica theológica-política de lo sucedido en el santo negozio de la Conçepción Immaculada de la Virgen Santíssima. Primera parte. De lo sucedido en tiempo del rey nuestro señor Felipe Tercero: 4 y ss. 
pacificis. Con él, se abstenía de introducir novedad alguna en la presente causa, limitándose a renovar los decretos de sus antecesores al respecto sin dar la razón a ninguna de las partes enfrentadas. ${ }^{25}$ Una segunda declaración pontificia, aparecida justo un año después, bajo el título Sanctissimus Dominus Noster, vendría a completar ésta, al reconocer a los devotos de la Purísima poder sostener públicamente que María había sido concebida sin pecado original, pero sin atacar en ningún caso a quienes defendieran el sentir opuesto, a quienes se les prohibió afirmar lo contrario en sermones, lecciones y cualquier otro acto público, que no a través de la letra impresa. ${ }^{26}$

Lejos de apaciguar las tensiones, tales disposiciones trajeron consigo un recrudecimiento de la controversia, al que no escapó el padre Tosantos, cuestionado por los propios inmaculistas partidarios de que otra persona más adecuada se hiciera cargo de la embajada romana. Empezó a sonar con fuerza el nombre de fray Pedro González de Mendoza, franciscano, otrora arzobispo de Granada y ahora de Zaragoza, a quien el rey llegó a ofrecerle el encargo. ${ }^{27}$ Podrían más, sin embargo, las ansias de medrar del religioso, que antes de enfrentarse al todopoderoso confesor regio -deux et machina del patronato real, por cuyo despacho pasaban tantos nombramientos eclesiásticos- y sacrificar su carrera prefirió declinar tal responsabilidad. Según voces autorizadas de la corte,

“El tacaño del arzobispo de Zaragoza se excusó, y cierto, señor, que yo no hallo en él otra cosa buena sino el hábito franciscano [...]. Como pretendiente, espera más del padre confessor que de Dios, ni de su Madre ni del rey".28

Así las cosas, Felipe III encomendaría el negocio al también franciscano obispo de Osma, el padre Francisco de Sosa. Siguiendo instrucciones de la Santa Sede, el nuncio se opuso con todas sus fuerzas al envío del nuevo embajador a Roma, recabando la ayuda de fray Luis Aliaga para hacer entrar en razón al monarca. Poco podría hacerse por ahora, en opinión del dominico, al

"[...] ser ésta una trama tan sutilmente hurdida bajo capa de devoción por los padres franciscanos, a impulso de los jesuitas, por medio de la señora infanta, tía de su magestad, religiosa descalza de san Francisco y tan arraigada en el corazón del rey que no veía de impedir [la embajada]". ${ }^{29}$

El único modo de abortar la legacía radicaba para el confesor en la posibilidad de que el papa escribiera de su puño y letra al rey exponiéndole, "categórica y resueltamente", que nada ni nadie iba a arrancarle la confirmación dogmática de

25 Bullarium Romanum: XII, 356.

26 Ibídem: XII, 396.

27 Para los interesados en la figura de este prelado, Pérez L. 1935. "Posición del arzobispo don fray Pedro González de Mendoza en la controversia sobre la Inmaculada Concepción". Archivo Iberoamericano XXXVIII: 45-75.

28 Pou y Martí, J. M. 1931. “Embajadas de Felipe III a Roma pidiendo la definición de la Inmaculada Concepción". Archivo Iberoamericano XXXIV: 509.

29 Archivo Secreto Vaticano[=ASV]. Fondo Borghese, serie 7, vol. 967: 167. la Inmaculada Concepción. Ignoramos si la carta en cuestión llegó a ser redactada o no. Lo único cierto es que Felipe III, fallecido el padre Sosa prematuramente, pospondría sus planes a la espera de que una nueva junta de teólogos volviera a examinar el asunto. ${ }^{30}$

\section{LA SEGUNDA JUNTA CONCEPCIONISTA}

A comienzos de diciembre de 1617 quedaba constituida la segunda junta concepcionista, compuesta entre otros por el cardenal Zapata, el arzobispo de Toledo don Bernardo de Sandoval y Rojas y los ya citados ordinarios de Cuenca y Valladolid. A ellos se sumaría en el último momento, por deseo expreso del rey, ni más ni menos que fray Luis Aliaga. ${ }^{31}$ La designación del dominico, cuyo peso religioso y político a nadie escapaba ya por entonces, ${ }^{32}$ produjo reacciones encontradas. De un lado los franciscanos, que excluidos de la cita por su partidismo cargaron airadamente contra el confesor, objeto también de las críticas por parte de los inmaculistas en general. ${ }^{33} \mathrm{Y}$ del otro el nuncio, quien se las prometía felices no sólo con la presencia del confesor, sino también la del cardenal Zapata, tal y como informó a Roma:

"El cardenal Zapata promete secretamente a Nuestro Señor todos sus buenos oficios en lo de la Concepción de Nuestra Señora, estorbando cuanto pueda que, sin fundamento, se moleste más a su santidad en cosa que no ha de conseguirse. Lo mismo hará el padre confesor, quien añade que le quiere hacer de ello cargo de conciencia; porque dice que se quiere hacer fuerza a la cabeza de la Iglesia en cosa puramente eclesiástica y poner leyes al Espíritu Santo". ${ }^{34}$

Como quiera que fuese, junto a los demás integrantes de la junta, el padre Aliaga debería examinar el último decreto romano en materia concepcionista, informando puntualmente de "los cavos que della resultasen, con necesidad de extensión o declaración, con los inconvenientes que, de no hacerse, podían resultar". ${ }^{35}$ Para ello, se reunirían hasta en cinco ocasiones, todas con una decisiva participación de nuestro protagonista, cuya opinión diferiría casi siempre del parecer mayoritario de los restantes convocados, más inclinados que él -incluido el cardenal Zapata- a satisfacer la devoción inmaculista del soberano.

El 13 de diciembre, sin ir más lejos, fray Luis emitía un voto particular frente a los partidarios de presionar al

30 AEESS. Ms. 446: 45.

31 Tanto fue así que "como llegó un poco tarde la orden de que entrasse en la junta, estaban ya sentados quendo él vino a ella, y el obispo de Cuenca en el lugar que le tocava; y se levantó y le dexó al padre confesor. $Y$ aunque no les pareció a todos que se debía mudar, lo hizo diciendo: No ay cossa que no se deva al confessor del rey". Ibídem: $47 v$.

32 De ahí las recomendaciones del nuncio al papa y al cardenal Borghese, en orden a que "su santidad y vuestra señoría illustríssima muestren con él toda la benignidad posible". Cit. Pérez Bustamante, C. 1934. "Los cardenalatos del duque de Lerma y el infante don Fernando de Austria". Boletín de la Biblioteca Menéndez Pelayo XVI-3: 249.

33 Frías, L. 1905, "Felipe III y la Inmaculada Concepción. Instancias a la Santa Sede por la definición del misterio". Razón y Fe 12: 189-190.

34 ASV. Segr. Stato, Spagna 60E: 549.

35 AEESS. Ms. 446: 46-46v. 
pontífice para obtener una declaración definitiva que atajara los escándalos acaecidos desde hacía años en todos los rincones de la Monarquía. Según el religioso "no había qué innovar aora en lo decretado y que, quando se sucediesen escándalos, se verá por ellos lo que se ha de suplicar a su santidad. Y que, entretanto, no aconsejará a su magestad haga nuevas instancias con el papa". ${ }^{36}$

Dos días más tarde completaba su dictamen el padre Aliaga manifestando su satisfacción con el contenido y alcance del breve Sanctissimus Dominus Noster:

"[...] el decreto tiene todo lo necesario y conveniente, y lo que dizen que falta no lo quiso dar su santidad; y que assí, en casso que se le aia de pedir alguna cosa, ha de ser sin manifestarle intención ni desseo particular, sino que su santidad juzgue libremente lo que le pareciesse conveniente al bien universal de la Iglesia". ${ }^{37}$

El 21 de diciembre fray Luis volvía a desmarcarse del sentir general de la junta, partidaria de pedir a Roma una definición dogmática, imponiéndose mientras silencio absoluto en esta materia. Si la corona se decidía por semejante posibilidad, advertía el padre confesor, debía dejar libertad a la Santa Sede para pronunciarse en uno u otro sentido, pero no necesariamente a favor de la Inmaculada Concepción, sobre la que podría seguir hablándose hasta que se produjera tal declaración. O dicho de otro modo, que "se pida la declaración con la moderación que se debe pedir al papa, sin que las diligencias sean más fuertes ni de más diferencia de lo que fuere la petición; y que el silencio no se debía pedir". 38

Sería con el nuevo año, no obstante, cuando el dominico diera mayores explicaciones sobre su postura, por escrito y a través de cinco largos pliegos fechados en el mes de enero. Con un distingo teológico fundamental entre los partidarios del sentir afirmativo -o inmaculistas- y los seguidores de la opinión negativa -o inmaculistas- inició el padre Aliaga su extenso argumentario:

"[...] los de la [opinión] afirmativa atienden a confesar maior diferencia entre Christo y su Madre y maior dependencia de la Madre al Hijo, y tiene esto por la mayor veneración de ambos; y los de la [opinión] negativa, piensan que es maior honor de los dos que la Madre no tuviesse culpa original. Y de aquí se conoce que la intención de ambas sentencias es buena y loable". ${ }^{39}$

Luego si esto era así, proseguía el confesor, en tanto la Santa Sede no dispusiera lo contrario -y no lo había hecho con su última declaración- ambos sentires eran igualmente válidos. Por supuesto que una definición libre y no predeterminada, como ya había sostenido, podría ser pertinente en las actuales circunstancias; y ello por diferentes razones, fuera para dar satisfacción a la piedad de los fieles o enseñar indubitablemente la verdad. Pero cómo pedirla al pontífice, se preguntaba fray Luis:

\footnotetext{
36 Ibídem: 62v-63.

37 Ibídem: 63

38 Ibídem: 64v.

39 Ibídem: 74.
}

"[...] a de ser proponiendo su magestad sencillamente el estado de las cossas y representando sin encarecimiento su devoción, de manera que sólo se tenga sencilla petición, de tal forma que con representar la devoción se represente también la indiferencia, promptitud y gusto con que su magestad abrazará lo que la Iglesia determinare. Y que esto conviene para que, en caso que su santidad defina que Nuestra Señora no tuvo pecado original, no puedan los hereges maliciar que fue gracia hecha a ynstancia de su magestad, ni decir que las demás cossas definidas se hicieron a semejanza desta por dar satisfación a príncipes". ${ }^{40}$

El silencio absoluto que algunos reclamaban para el maculismo mientras Roma se pronunciaba, proseguía el dominico, ni podía ni debía solicitarse, porque no pocos padres de la Iglesia, santos y teólogos habían fundado éste en las Sagradas Escrituras. Y ninguno mejor que san Buenaventura o santo Tomás de Aquino, cuya doctrina había hecho suya la orden de Predicadores ya en el Medievo. De manera que, "siendo assí que esta doctrina contraria es común de los santos, es conforme a la piedad de la fe, es más segura, mal se puede pensar que, contra ella, pueda su santidad poner perpetuo silencio si no es por la definición" ${ }^{41}$

En cualquiera de los casos, aclaraba el padre Aliaga, cuantos autores habían defendido la sentencia afirmativa lo habían hecho con prudencia, ateniéndose siempre a los dictados romanos. Sólo tres grandes plumas, Cayetano, Cano y Medina, habían escrito del asunto a lo largo del último siglo. Ni siquiera los dominicos predicaban ya sobre el particular ni hablaban de él en actos académicos o conclusiones, cumpliendo el último dictamen pontificio. A ninguno de ellos podía responsabilizárseles de los escándalos que se les atribuían; al contrario,

"El escándalo que ay naze de que no se ha hecho con el pueblo lo que se debía, enseñándole la probabilidad y verdad de la opinión afirmativa. Y que assí, siendo el pastor supremo el papa, no debe poner el silencio que se pide, sino que hazer que al pueblo, que no sabe, se le enseñe lo que es menester que sepa, para que salga del escándalo que padece sin razón de una doctrina que la Iglesia tiene calificada tantas vezes por buena". ${ }^{42}$

Excesos, en fin, concluía fray Luis, los había habido en todas partes, a cuenta de maculistas e inmaculistas. Quizá conviniera que el nuncio comisionara a alguien, ecuánime y sin intereses ningunos en esta causa, para esclarecerlos y castigar ejemplarmente a sus responsables, tal y como habían solicitado ya los dominicos "y no se les concedió". ${ }^{43}$

Los pliegos del confesor acabaron en manos del monarca, quien sabemos los cometió a un tercero para su examen, listo a comienzos de febrero de $1618 .{ }^{44}$ El anónimo informante rebatiría hasta la última de las afirmaciones del religioso, cuyas principales proposiciones fueron calificadas de parciales y falsas -particularmente en lo referente al modo de solicitar la definición, el silencio que debía imponerse al maculismo o los escándalos ocasionados por esta contro- $\begin{array}{ll}40 & \text { Ibídem: } 75 \mathrm{v} . \\ 41 & \text { Ibídem: } 77 \mathrm{v} . \\ 42 & \text { Ibídem: } 78 . \\ 43 & \text { Ibídem: } 78 v . \\ 44 & \text { Ibídem: } 80-84 v .\end{array}$ 
versia- según el sentir general de la segunda junta reunida por Felipe III, de lo que puede deducirse que tal refutación fue escrita por uno de sus miembros. ${ }^{45}$ Posiblemente el mismo personaje, o alguien próximo a él, airearía las afirmaciones del padre Aliaga, al que llovieron no pocas críticas. En especial las del ya citado arzobispo de Zaragoza fray Pedro González de Mendoza, que arremetió con dureza contra él culpando a la orden de Predicadores de todos los disturbios acaecidos a lo largo y ancho de la Monarquía desde los incidentes sevillanos protagonizados por sus frailes, "que andavan por la calle diciendo que se espantavan tuviesen tanta devoción y piedad con la Madre descendientes de los que no la avían tenido con el Hijo, y esto es lo que movió al pueblo y le alteró contra ellos". ${ }^{46}$

\section{LA GRAN JUNTA DOMINICANA DE ATOCHA}

Coincidiendo con las nuevas censuras antidominicanas, comenzaron a alzarse algunas voces -fuera, pero también dentro de la propia orden- partidarias de que el rey mandara a los frailes de santo Domingo conformarse con la opinión mayoritaria de los fieles, y de la misma corona, en materia concepcionista. Varias fueron las peticiones formales elevadas al soberano en este sentido, como la siguiente:

"Es la orden de santo Domingo hija de España; es la mayor fortaleza que la fee tiene en estos reynos; por la doctrina que sigue está desacreditada de seys años a esta parte y la pierde el reyno la aficción tan merecida. Puede y debe vuestra magestad poner cura en esta religión. Puédeseles proponer a los mismos padres que su orden es la maestra de España, por la qual excelencia debe conformarse con vuestra magestad y sus reynos en el sentir del magisterio que se platica $[\ldots]^{\prime \prime} .47$

Felipe III participó el asunto a fray Luis Aliaga, quien a su vez lo elevó al Provincial de España, no otro que el padre Antonio de Sotomayor, para ponerlo en conocimiento del Maestro General de la orden fray Serafino Sicco y conocer su parecer en "el negocio más apretado que quiçás ha tenido la religión [de santo Domingo]". Sin aguardar a éste, confesor y Provincial elaboraron un memorial dirigido al rey para defender su postura al respecto de la polémica concepcionista. Cierto que los hijos del Patriarca de Caleruega, reconocían ambos, no predicaban sobre el caso igual que el resto de órdenes, lo cual "no nacía de amor proprio, ni de pasión o protervia, que nunca se a allado en esta religión en cosa disconveniente, sino de ver por la sentencia negativa tantos y tan apretados y patentes testimonios de los santos", y porque estimavan no ser lícito "desamparar la doctrina común, conocida de los santos, por causas temporales, aunque se considerasse la otra sentencia con los accidentes que le había dado la devoción de los fieles". Esos mismos religiosos, proseguían los padres Aliaga y Sotomayor, no se oponían a nada ni a nadie; al contrario, limitábanse a observar los decretos de los romanos pontífices en este

45 "Entiéndese que fue el obispo de Cuenca", se lee en una nota marginal al texto. Ibídem: $84 \mathrm{v}$.

46 Cit. Pérez, L. 1945: 46.

47 Cit. Canal, M. 1932: 149. particular, "y ansí por ellos no era turbada la paz, pues con tanta modestia y prudencia callavan y sufrían las injurias que los enemigos les hacían". Luego "religión que con tal prudencia se gobernava -concluían- ni estaba enferma ni tenía necesidad de cura". ${ }^{48}$

Por lo que parece las palabras de fray Luis y fray Antonio no mudaron el ánimo del rey, convencido de la necesidad de que los dominicos se replantearan su postura. Tanto que, en el mes de mayo de 1618, instó a ambos a tomar "algún buen medio para hacer la execución de sus intentos" a partir de una [gran] junta en la que se dieran cita los frailes más reputados de la Provincia de España, "Ios quales se allanasen a pedir a su santidad les ordenara lo que debían hazer en este caso". De modo que, si finalmente eran reconvenidos por la corona para rezar o predicar en conformidad con el inmaculismo, pudieran hacerlo con la conciencia tranquila y sin contradicción ninguna.

No debió de realizarse esta consulta al papa, pero sí al Maestro General de la orden, a quien el confesor regio escribió con preocupación a la espera de instrucciones:

“[...] le parece a su magestad que esto es tan justificado que no podemos raçonablemente evadirnos de concederlo" 49

En ello insistiría el padre Aliaga a fray Serafino Sicco por medio del prior del convento de Nuestra Señora de Atocha, enviado a Portugal, donde se reunía el capítulo general dominicano, ${ }^{50}$ para entregarle un informe confidencial del confesor. Por él sabría la máxima autoridad de la orden de los infinitos pesares que los frailes de santo Domingo venían padeciendo en España hacía ya más de un lustro, ante la pasividad de la corona y el silencio de Roma, como consecuencia de su defensa de la opinión afirmativa en materia concepcionista. Situación agravada tras la promulgación del breve Sanctissimus Dominus Noster:

"Este decreto de su santidad no ha sido guardado de nadie en la parte que dize que no se trate de la opinión contraria y hace executado en la parte que es favorable a la opinión que llaman pía, de donde resulta la persecución de la orden, que la tienen por contraria; descrédito della el haberse movido todas las universidades a favor de la opinión pía y confirmándose en ella los que la tenían y aumentándose el número dellos, de tal manera que tiene la orden contra sí en la materia las personas reales, los grandes, el pueblo, las religiones, las universidades en virtud del mismo decreto, a su santidad y cardenales que se lo aconsejaron, pues quanto quieran que dejen nuestra opinión por probable, pero no quieren que se enseñe en la Iglesia. De donde se infiere que el tener nuestra opinión se juzga por porfía el sustentarla. De donde también se infiere la justificación de su magestad, que es querer que en sus reinos todos enseñen aquella doctrina"

48 Ibídem: 151.

49 Ibídem: 152.

50 Acta capituli generalis Ulyssipone in conventu Sancti Dominici ordinis Praedicatorum, celebrati in festo Sanctissimae Pentecostes III, iunii anno Domini MDCXVIII, en Reichert, B. 1895-1935. Monumenta ordinis Praedicatorum Historica: XI, 294 y ss. Lovaina - Roma: Ordinis Fratrum Praedicatorum. 
Era el momento, pues, de que el Maestro General confiriera el asunto directamente con Paulo $\mathrm{V}$ para conocer de primera mano a qué debía atenerse la orden de Predicadores, $\mathrm{y}$

"[...] si su santidad quiere que la orden no desista, sino que tanga la doctrina que manda que no se enseñe a la Iglesia, mándele a la orden que lo haga assí. Pero mandar en lo público que no se enseñe la doctrina y mandar en secreto que la orden no la deje, como estoy informado que vuestra paternidad reverendíssima señala, no es amparar la doctrina de los santos, y es no solamente desamparar la orden, pero antes aventurarla y perderla"..$^{51}$

Entretanto, el 24 de junio de 1618, en Nuestra Señora de Atocha y presididos por el confesor, se reunía la gran junta dominicana propuesto por Felipe III, quien a través del ya cardenal duque de Lerma, protector de la orden de santo Domingo, instó a los asistentes a que la Provincia de España suplicara al papa les ordenara rezar, celebrar y predicar la Inmaculada Concepción de la Virgen María del modo en que lo hacía el resto de la Iglesia. ${ }^{52}$

La cuestión generó la división entre los convocados. De un lado aquellos religiosos como los padres Baltasar Navarrete, Diego Lorenzana, Bernardino de Ayala, Juan de Pereda, Francisco de Sotomayor, Pedro de Olivares, Cristóbal de Torres, Francisco Sotomayor y Jacinto de la Plaza, partidarios de no tomar decisión ninguna sino a través del Maestro General, a quien consultarían en tal sentido. Del otro una minoría de frailes dispuestos a complacer a la corona con tal de no perjudicar a la orden de Predicadores, sorprendentemente acaudillados por fray Luis Aliaga, y a su lado el Provincial de España. Hablamos de los padres Juan y Tomás González y Lorenzo Gutiérrez, catedráticos de la Universidad Complutense; Alonso Barrantes, prior del convento de San Pedro Mártir de Toledo; Juan de la Puente, cronista real; y Pedro Benero, rector del colegio de Santo Tomás de Alcalá de Henares. Los ocho escribirían al pontífice según la voluntad del soberano, "porque estamos dispuestos, con prompta obediencia y humildad, a recibir de essa Santa Sede todo lo que de ella nos viniesse, assí en esta materia como en otras". 53

\section{LA TERCERA JUNTA INMACULISTA}

Vistos los resultados de la junta habida en el convento de Nuestra Señora de Atocha, Felipe III suspendió la convocatoria de reuniones similares en las restantes Provincias dominicanas de la Monarquía, previstas originalmente. Agradeció a su confesor, aún así, el empeño mostrado en la reunión para hacer prevalecer los regios deseos, confiados ahora a las gestiones de un enésimo embajador extraordinario ante la Santa Sede, fray Antonio de Trejo, vicario

51 Cit. Canal, M. 1932: 155.

52 AEESS. Ms. 446: 101v-102.

53 Ibídem: 102. En un principio se pensó entregar esta carta al papa por medio de uno de los citados, el padre Gutiérrez, porque "a de ser poderosíssima cosa y que a de mover grandemente al papa y a toda Roma ver un fraile dominico pidiendo con veras y fuerça lo que toda la christiandad desea". Cit. Frías, L. 1905: 327-328. general de la orden de san Francisco, preconizado obispo de Cartagena y hermano del cardenal de igual apellido. ${ }^{54}$ $\mathrm{Ni}$ oír hablar de esta legacía quiso el Paulo V, como transmitió al nuevo nuncio en Madrid Francesco Cennini, arzobispo de Amelia, encargado de boicotear la misión del padre Trejo auxiliado por fray Luis Aliaga, ${ }^{55}$ desde enero de 1619 Inquisidor general apostólico de España y todos sus señoríos en pago a los servicios prestados a la corona, en éste y otros menesteres. ${ }^{56}$

El dominico, que en su más que probable ambición por ceñir pronto un capelo necesitaba tanto complacer al pontífice como no contrariar la devoción inmaculista del soberano, volvió a desenvolverse con extraordinaria habilidad. En esta ocasión daría pábulo a los rumores según los cuales el embajador dedicaba más tiempo a las intrigas políticas que a la Purísima, recabando apoyos entre los cardenales con derecho a voto en el próximo cónclave para entronizar en la cátedra de San Pedro un candidato favorable a los intereses españoles, con el lógico enojo del actual pontífice y el consiguiente perjuicio para la empresa inmaculista. Así lo expuso por lo menos al rey:

"El obispo de Cartagena a dado justa causa a que no lo oygan de buena gana, pues a tratado con algunos cardenales de la futura elección de pontífice y dicho otras palabras que mostraron amenaza. $Y$ que todo esto es cierta cosa que avrá llegado a oídos del papa y de su sobrino y que lo avrán sentido tiernamente. Por lo qual, ni la causa pía que él tiene a cargo de tratar, ni la autoridad de vuestra magestad, que a ello le embió, puede tener el fruto que se desea". ${ }^{57}$

Antes de tomar ninguna determinación quiso el monarca conocer la opinión de la junta de teólogos que, constituida tiempo atrás, volvería a reunirse, en esta ocasión en casa del mismísimo confesor y bajo su presidencia, el 9 de abril de 1619. Apenas costaría esfuerzo al religioso, desde la atalaya de su nueva condición de Inquisidor general, doblegar el ánimo de los convocados. ${ }^{58}$ Todos unánimemente vota-

54 Además de los tantas veces citados trabajos de L. Frías, sobre la figura de éste puede verse Molinero, M. R. 1955. "Fray Antonio de Trejo y el movimiento inmaculista en la diócesis de Cartagena". Archivo Iberoamericano XV: 1057-1076, y López García, Mª. T. 2005. “El auge del dogma de la Inmaculada Concepción auspiciado por el franciscano fray Antonio de Trejo, obispo de Cartagena, y la implicación del Concejo de Murcia a principios del siglo XVII", en La Inmaculada Concepción en España: religiosidad, historia y arte: I, 119-138. Madrid. Los avatares de su embajada fueron descritos por su colaborador Waddingus, L. 1641, Legatio Philippi III et IV catholicorum reggum Hispaniarum ad Paulum papam $V$ et Gregorium XV de definienda controversia Inmaculatae Conceptionis Beatae Virginis Mariae. Amberes: Petrum Bellerum.

55 ASV. Segr. Stato, Spagna, 341: 47-49.

56 Archivo Histórico Nacional[=AHN]. Inquisición. Lib. 592, f. 174. Los años del padre Aliaga al frente del Santo Oficio en Galván Rodríguez, E. 2010. El Inquisidor general: 84-98. Madrid: Dykinson.

57 AEESS. Ms. 446: 144v-145.

58 "Esto lo dieron por cierto y asentado sin más fundamento que averlo referido assí en la junta el padre confessor. Que aunque es cierto no lo fingiría, pero no se puede dudar que tendría estas noticias por aviso de los dominicos de Roma, como después advirtió el obispo de Cartagena, y aquí entrava el pensar que podría ser falso testimonio y calumnia de los contrarios para descomponer al obispo y librarse ellos del peligro en que se vían por sus diligencias e istancias, y esto era fácil de creer sabiendo que no omitían medio que no aplicassen para su intento". Ibídem:145v-146. 
rían por el inmediato retorno de fray Antonio de Trejo, añadiendo a renglón seguido, para tranquilidad de la corona, que "no por esto se desista de lo que está pedido, antes bien se prosiga con el embajador [ordinario] duque de Alburquerque". ${ }^{59}$

Tan radical determinación no satisfizo a Felipe III. De hecho, devolvería a la junta su última consulta instando a su presidente a buscar una solución intermedia. Efectivamente, los eclesiásticos volverían a reunirse el día 19 de abril para discutir sobre las cosas que podían o no solicitarse al pontífice en lugar de la pretendida confirmación dogmática de la Inmaculada Concepción. No hubo acuerdo esta vez, determinándose que, cada uno de los participantes, representase por escrito al soberano su propio parecer. Entre los más extensos e interesantes, cómo no, el del padre Aliaga, cuya introducción delataría el tono de su contenido:

"El estado de esta causa es tal que para mí tuviera por más fácil decir mi parecer en un concilio que aquí. Porque en el concilio se admitiera con sana intención y en España se tiene por pasión lo que a su magestad se aconseja no siendo a gusto de quien lo sabe. $Y$ si de esto naciera solamente nota en la persona que dice su parecer, importava poco, porque es fácil aventurarse a accidentes por no faltar a la verdad en la forma que la entiende quien habla. Pero que resultarán daños al estado de la causa porque se hace como nueva materia de emulación, y por ventura si esto no huviera sido se hubieran dado algunas advertencias que de ellas se pudiera entender no avían de resultar inconvenientes". 60

Hecha tal advertencia, el dominico iba a fundar su parecer, contrario a la continuidad de la embajada extraordinaria, en la fría acogida dispensada por el pontífice a los diferentes legados que se habían ocupado de ella así como en los escasos avances por éstos logrados, elementos ambos perjudiciales para la causa de la Purísima. Lo mejor era, por tanto, que el padre Trejo abandonara de inmediato Roma, "y que entienda su santidad la causa porqué se le manda venir a su residencia, que este es el único medio que ay para disponer el ánimo del papa a conceder lo que se le quisiere pedir", fuera esto lo que fuere, añadió sutilmente fray Luis. De ello podría ocuparse en lo sucesivo, si así se estimaba oportuno, el duque de Alburquerque don Francisco Fernández de la Cueva, en su calidad de embajador de la Monarquía ante la Santa Sede. ${ }^{61}$

$Y$ es que, según el confesor, Paulo $V$ seguía muy de cerca y con preocupación cuantos acontecimientos venían produciéndose en España alrededor de esta polémica que ninguna declaración pontificia había conseguido zanjar. El mejor ejemplo de ello era lo recientemente ocurrido en Valencia, diócesis regida desde 1612 por su hermano fray Isidoro, quien llevaba años padeciendo las afrentas e injurias de los inmaculistas por el solo hecho de hacer cumplir la legislación vigente en materia de la Concepción. ${ }^{62}$

59 Ibídem:145.

60 Ibídem:151v-152.

61 Ibídem: 152.

62 Callado Estela, E. 2012., Sin pecado concebida. Valencia y la Inmaculada Concepción en el siglo XVII: 29 y ss. Valencia: Institució Alfons el Magnànim.
Recientemente había vuelto a publicarse en aquella ciudad, sin la preceptiva autorización eclesiástica, la vieja pragmática de Juan I de Aragón sobre el particular, monumento a la Pulcra María -promulgado en 1394- contra los maculistas de los territorios catalanoaragoneses, a quienes se les prohibió terminantemente enseñar o predicar contra ella. ${ }^{63}$ Exigía el dominico que la corona tomara cartas en el asunto para aclarar

“[...] si en aquella pragmática ay alguna cosa de lo que la Iglesia tiene vedado o permitido, o si fuera de esto mismo ay algo desconforme a los decretos de la Iglesia, porque si en España, por una parte, se publicasen cosas con estos achaques o parte de ellos, podría ser que sobre la disposición que oy tiene su santidad se le criase otra poco conveniente a lo que vuestra magestad desea". ${ }^{64}$

Únicamente con contundencia podrían aquietarse los ánimos de una vez por todas, entre los defensores de la opinión afirmativa, como siempre se había hech, por supuesto, pero también entre los del sentir negativo, quienes seguían actuando impunemente, ahora contra lo estipulado en el breve Sanctissimus Dominus Noster

“[...] si agora los ánimos no están quietos, no es por la oposición de la opinión contraria, porque si de alguno se a entendido que a excedido en predicar contra el decreto, tratando de la dotrina de que Nuestra Señora fue concebida con pecado original, se ha tratado y trata de su castigo. Y es creíble que, en la opinión contraria, no todos an tratado del decreto puntualmente y no se a tratado de castigar a ninguno". ${ }^{65}$

Como el confesor regio ningún otro miembro de la junta se mostraría partidario de mantener en Roma al obispo de Cartagena, así que Felipe III acabó ordenando su vuelta a la corte. De las gestiones sucesivas en el negocio concepcionista se encargaría a partir de entonces, según lo propuesto por fray Luis, don Francisco Fernández de la Cueva, duque de Alburquerque, cuyas diligencias ante el reticente Paulo $\checkmark$ no iban a correr mejor suerte que las de los embajadores extraordinarios.

$$
* * * * *
$$

Podría decirse, en fin, que fray Luis Aliaga se había salido con la suya en este asunto, asestando un duro golpe a los devotos de María Inmaculada. Despojados éstos de su portavoz en la corte de los papas, verían alejarse en el horizonte la esperanza de una pronta definición dogmática, de la que ya no se ocuparía junta alguna tras la disolución de la última, sin continuidad durante el siguiente cuarto de siglo. No era la primera vez que los inmaculistas acusaban al dominico de todos sus males. Ahora, sin embargo, recrecerían las críticas

63 1619. Plegmática del molt alt senyor rey de Aragó, traduhida del Ilatí en vulgar valencià, Valencia: s.e.. Véase en cualquier caso 1515. Aureum opus regalium privilegium civitatis et regni Valentiae : 156. Valencia : Didaci de Gumiel. El decreto original fue editado por Gazulla, F. 1906. "Los reyes de Aragón y la Purísima Concepción de María Santísima". Boletín de la Real Academia de Buenas Letras de Barcelona 21: 391-392.

64 AEESS. Ms. 446: 152v.

65 Ibídem:153. 
contra él, que "lo ha fraguado todo en secreto". De las malas artes empleadas hasta entonces por el confesor alertarían al duque de Alburquerque, recomendándole a comienzos de 1620 que se guardara de él, evitando cualquier comunicación con la corte que no fuera dirigida directamente al rey, porque de la extinta junta "faltan todos los buenos y quedan todos los malos, y siempre que los junten dirán y harán quanto quisiere el confesor", quien, "como poderoso y privado, los atemoriza a todos, y como parte es enemigo". ${ }^{66} \mathrm{E}$ mes de diciembre del mismo año volvían a cargar sobre el padre Aliaga después de que Felipe III, a instancias suyas, desistiera de celebrar un solemne juramento a la mayor gloria de la Purísima Concepción, similar al que municipios, universidades y colectivos de la Monarquía venían tributando a tal misterio desde hacía tiempo, ${ }^{67}$ sin la autorización previa de la Santa Sede. Del siguiente modo lo describiría un testigo presencial de tales hechos:

\begin{abstract}
"Vine de Talavera a hallarme en el octavario de la Concepción y en el juramento que avía de hacer su magestad que estaba público en todo el mundo y lo había escrito la señora infanta a Flandes al archiduque, su hermano, y pueden tanto las buenas letras del señor Patriarca y el cuidado que tiene de dar gusto al padre confesor, que propuso no convenía que su magestad jurase sin pedir licencia al papa; y la bondad de su magestad es tanta que acordó de pedirla". ${ }^{68}$
\end{abstract}

Se entiende, pues, que la caída en desgracia del dominico, sobrevenida a la muerte del monarca, en marzo de 1621, y materializada en la privación del confesionario regio y el abandono de la Inquisición general, ${ }^{69}$ hiciera renacer la esperanza de los inmaculistas.

Casualidad o no del destino, los cambios políticos operados en España coincidirían con los inicios de un nuevo pontificado, en la persona de Gregorio XV, quien tampoco se mostraría especialmente proclive a esta causa mariana, si bien las presiones de Felipe IV lograrían arrancarle en 1622 un nuevo breve, en virtud del cual quedaría prohibido en lo sucesivo, no ya sólo en público -según lo declarado por Paulo V- sino también privadamente, en conversaciones o por escrito, la sentencia afirmativa que sostenía que la Virgen había sido concebida en pecado. Es decir, que la opinión maculista era condenada al silencio, y aunque sus partidarios pudieran continuar sintiéndola en su fuero interno, no podrían manifestarla externamente ni tratar de ella con otros. $^{70}$

66 Pou y Martí, J. M. 1933. "Embajadas de Felipe III a Roma...". Archivo Iberoamericano XXXVI: 38-39.

67 Al respecto véanse, entre otros, Gómez, O. 1955. "Juramentos concepcionistas de las universidades españolas en el siglo XVII". Archivo Iberoamericano XV: 867-1045.

68 Cit. Frías, L. 1906. "Felipe III y la Inmaculada Concepción. Instancias a la Santa Sede por la definición del misterio". Razón y Fe 13: 74-75.

69 Elliott, J. H. 1990. El conde-duque de Olivares: 93 y 119-122. Barcelona: Crítica.

70 Bullarium Romanum: XII, 688. No obstante, su cláusula final "exceptis tamen quibus a Sancta Sede Apostolica fuerit super hoc specialiter indultum", posibilitaría a los dominicos amortiguar el golpe con la obtención del decreto particular Eximii atque singulares, autorizándoseles a tratar y discutir entre ellos solos sobre la materia vedada. Ibídem: 717.
Nada pudo hacer esta vez fray Luis Aliaga, desterrado de la corte, enfermo y a punto de ser procesado por la Inquisición. ${ }^{71}$ Fue su hermano quien lo acogió en Valencia. Allí pudo contemplar la fortaleza del inmaculismo tras la última victoria venida de la Santa Sede, a partir de la celebración de unas fastuosas fiestas ${ }^{72}$ y la organización de un solemne juramento. ${ }^{73} Y$ ello pese a la oposición del ordinario diocesano y su propia presencia. Apenas restaban al otrora confesor unos meses de vida. ${ }^{74}$ En muy poco beneficiaría al misterio concepcionista su desaparición, como auguraron algunos. Por el contrario, el nuevo papa Urbano VIII nada iba a innovar en esta materia, que llegaría al mediar de la centuria sin haberse movido un ápice. ${ }^{75}$

\section{BiBLIOGRAFÍA}

Astrain, A.1912. Historia de la Compañía de Jesús en la asistencia de España: IV. Madrid: Razón y Fe. Lopetegui, I. 1974. "Renovación y fracaso de las tentativas para obtener una definición dogmática en la controversia de auxiliis". Archivo Teológico Granadino 37: 45-81.

Bonnefoy, J. F. 1955. "Sevilla por la Inmaculada". Archivo Iberoamericano XV: 7-33.

Borao, G.1869. Historia de la Universidad de Zaragoza: 113. Zaragoza: Imprenta de Calixto Ariño.

Broggio, P. 2009. La teología e la política. Controversie dottrinale, curia romana e monarchia spagnola tra Cinque e Seicento. Florencia: Leo S. Olschki Editore.

Broggio, P. 2013. "Teologia, ordini religiosi e rapporti política: la questione dell'Immacolata Concezione di Maria tra Roma e Madrid (1614-1663)". Hispania Sacra LXV: 255-281.

Callado Estela, E. 2002. "Parentesco y lazos de poder. Las relaciones del arzobispo de Valencia fray Isidoro Aliaga con su hermano fray Luis Aliaga, confesor regio e Inquisidor General", en Espacios de poder. Cortes, ciudades y villas (s. XVI-XVIII): I, 123-138. Madrid: Universidad Autónoma.

Callado Estela, E. 2005. "Documentos para la Historia del dominicano colegio zaragozano de San Vicente Ferrer". Archivum Fratrum Praedicatorum LXXV: 140-193.

Callado Estela, E. 2012., Sin pecado concebida. Valencia y la Inmaculada Concepción en el siglo XVII.. Valencia: Institució Alfons el Magnànim.

71 Acusado de proposiciones sospechosas de luteranismo y materialismo Pérez Villanueva, J., y Escandell Bonet, B. (dirs.). 1984. Historia de la Inquisición en España y América: I, 1070. Madrid: Biblioteca de Autores Cristianos.

72 Crehuades, J. N. 1623. Solenes y grandiosas fiestas que la Ciudad de Valencia ha concedido a favor de la Inmaculada Concepción de María. Valencia: Pedro Patricio Mey.

73 Callado Estela, E. 2012: 87 y ss.

74 Muerto finalmente en Zaragoza el año 1626. Archivo Histórico de la Provincia Dominicana de Aragón [=AHPDA]. Libros de Predicadores de Zaragoza. Ms. 1, Catalogus religiosorum defunctum huius regalis conventus Praedicatorum Caesaraugustae:349-349v.

75 Gutiérrez, C. 1955: 20 y ss. 
Canal, M. 1932. "El padre Luis de Aliaga y las controversias teológicas de su tiempo", Archivium Fratrum Praedicatorum X: 107-157.

Cortés Peña, A. L. 2001. "Andalucía y la Inmaculada Concepción en el siglo XVII", en Calderón de la Barca y la España del Barroco: I, 401-428. Madrid: Centro de Estudios Políticos y Constitucionales.

Feros, A.2002. El duque de Lerma. Realeza y privanza en la España de Felipe III. Madrid: Marcial Pons.

Frías, L. 1904. "Felipe III y la Inmaculada Concepción. Instancias a la Santa Sede por la definición del misterio". Razón y Fe 10: 21-33, 145-156 y 293-308, 12: 12 (1905), pp.

Frías, L. 1905. "Felipe III y la Inmaculada Concepción. Instan-cias a la Santa Sede por la definición del misterio". Razón y Fe 12: 322-336.

Frías, L. 1906. "Felipe III y la Inmaculada Concepción. Instan-cias a la Santa Sede por la definición del misterio". Razón y Fe 13: 62-75.

Razón y Fe, 10 (1904), pp. 21-33, 145-156 y 293-308; 11 (1905), pp. 180-198.

Galván Rodríguez, E. 2010. El Inquisidor general. Madrid: Dykinson.

García García, B. J. 1998. “El confesor fray Luis Aliaga y la conciencia del rey", en I religiosi a corte, teologia politica e diplomazia in Antico Regime: 159-194. Florencia: Bulzoni Editore.

Gazulla, F. 1906. "Los reyes de Aragón y la Purísima Concepción de María Santísima". Boletín de la Real Academia de Buenas Letras de Barcelona 21: 388-393.

Gutiérrez, C. 1955. “España por el dogma de la Inmaculada. La embajada a Roma de 1659 y la bula Sollicitudo de Alejandro VII". Miscelanea Comillas 24: 1-63.

Le Bachelet, X. 1927. "Immaculée Conception", en Dictionnaire de Théologie Catholique : VII, 1120 y ss. París : Gaume fréres et J. Duprey editeurs.

Llorca, B. 1954. "La autoridad eclesiástica y el dogma de la Inmaculada Concepción". Estudios Eclesiásticos 28: 299-322.

López García, Ma. T. 2005. “El auge del dogma de la Inmaculada Concepción auspiciado por el franciscano fray Antonio de Trejo, obispo de Cartagena, y la implicación del Concejo de Murcia a principios del siglo XVII", en La Inmaculada Concepción en España: religiosidad, historia y arte: I, 119-138. Madrid: s.e.

Martínez Peñas, L. 2007. El confesor del rey en el Antiguo Régimen. Madrid: Editorial Complutense.
Meseguer Fernández, J. 1955. "La Real Junta de la Inmaculada Concepción (1616-1817 / 20)", Archivo Iberoamericano XV: 621-866.

Molinero, M. R. 1955. "Fray Antonio de Trejo y el movimiento inmaculista en la diócesis de Cartagena". Archivo Iberoamericano XV: 1057-1076.

Navarro Latorre, J. 1981. "Aproximación a fray Luis de Aliaga, confesor de Felipe III e Inquisidor General de España", en Estudios del Departamento de Historia Moderna. Zaragoza: Universidad de Zaragoza.

Olazarán, J. 1946. "El dogma de la Inmaculada Concepción en el concilio de Trento". Estudios Eclesiásticos 20: 107-136.

Pérez Bustamante, C. 1934. "Los cardenalatos del duque de Lerma y el infante don Fernando de Austria". Boletín de la Biblioteca Menéndez Pelayo XVI-3: 237- 293.

Pérez Bustamante, C. 1950. Felipe III. Semblanzas de un monarca y perfiles de una privanza. Madrid: Real Academia de la Historia.

Pérez L. 1935. “Posición del arzobispo don fray Pedro González de Mendoza en la controversia sobre la Inmaculada Concepción". Archivo Iberoamericano XXXVIII: 45-75.

Pérez Villanueva, J., y Escandell Bonet, B. (dirs.). 1984. Historia de la Inquisición en España y América: I. Madrid: Biblioteca de Autores Cristianos.

Pou y Martí, J. M. 1931. "Embajadas de Felipe III a Roma pidiendo la definición de la Inmaculada Concepción". Archivo Iberoamericano XXXIV: 508-534.

Poutrin, I. 1997. "L'oeil et le souverain: Luis de Aliaga et le métier de confesseur royal sous Philippe III", en J. M. Scholz y Th. Herzog (Dirs.), Observation and Communication: The construcction of realities in the Hispanic World: 253270. Franfuert am Main: s.e.

Ros, C. 1988. La Inmaculada y Sevilla. Sevilla: Editorial Castillejo.

Sagües, J. 1954. "Trento y la Inmaculada. Naturaleza del dogma mariano", Estudios Eclesiásticos 28: 323-367.

Vázquez, I. 1979. "Las controversias doctrinales postridentinas hasta fines del siglo XVII", en Historia de la Iglesia en España IV. La Iglesia en la España de los siglos XVII y XVIII: 419-477. Madrid: Biblioteca de Autores Cristianos.

Vranic, S. 1966. "Carta de un ciudadano de Sevilla. La Guerra mariana de Sevilla en el siglo XVII". Archivo Hispalense XLIV: 241-274, y XLV: 59-77.

Zamora Mendoza, J. 1956. "Un logroñés ardiente defensor de la Inmaculada. Fray Felipe Bernal de Mena, religioso premostratense". Berceo 40: 277-296. 